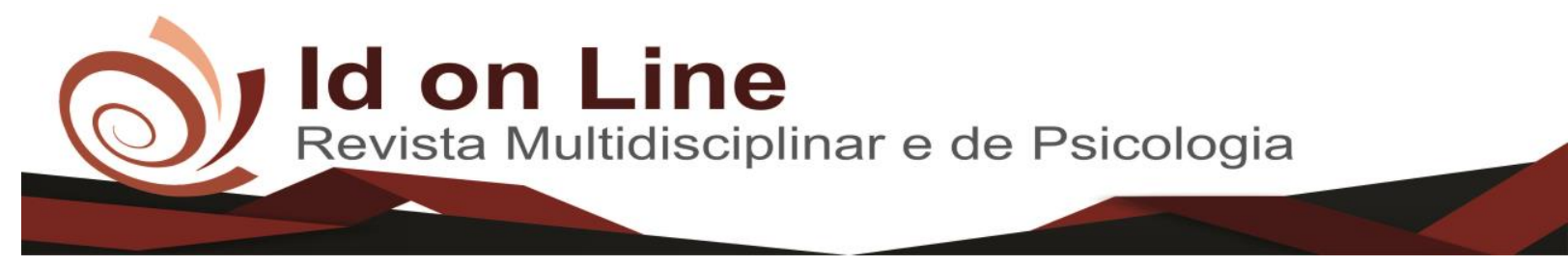

Artigo de Revisão

\title{
Diversidade Textual em Sala de Aula
}

\author{
Giselle Pupim Jorge Back ${ }^{1}$
}

\begin{abstract}
Resumo: Este artigo discute a produção de textos e a correção adotada pelo professor, propondo técnicas de produções e de ajustes textuais. As fontes para o embasamento teórico da pesquisa foram livros, revistas e internet, com autores como Bakthin (1997), Geraldi (2004), Jolibert (1994), Machado (2007), Marcuschi (2001), Matencio (2001), Miller (1998), Moscovici (2003) dentre outros. Para a coletas de dados foram utilizados os registros de cadernos dos discentes, entrevistas e documental. Tendo por objetivo compreender o espaço que a escrita ocupa na prática escolar dos alunos, referenciou-se uma sala de $5^{\circ}$ ano, do Ensino Fundamental, de uma escola pública no município de Alta Floresta - MT. Em observação, constatou-se que a prática de produção textual na escola é rotineira, no entanto não há um plano de intervenção que atinja a todos os alunos. Os resultados indicam que a prática de produção textual nas escolas deve ser repensada, tornando-se, mais significativa nos seus diversos contextos.
\end{abstract}

Palavras-chave: produção textual; prática docente, correção textual e plano de intervenção.

\section{Textual Diversity in Classroom}

\begin{abstract}
This article discusses the production of texts and the correction adopted by the teacher, proposing techniques of productions and textual adjustments. The sources for the theoretical basis of the research were books, magazines and internet, with authors such as Bakthin (1997), Geraldi (2004), Jolibert (1994), Machado (2007), Marcuschi (2001), Matencio 1998), Moscovici (2003), among others. For the collection of data were used the records of students' books, interviews and documentary. In order to understand the space that the writing occupies in the students' school practice, a 5th grade room, of the Elementary School, of a public school in the municipality of Alta Floresta - MT was referenced. In observation, it was verified that the practice of textual production in the school is a routine, however there is not an intervention plan that reaches all the students. The results indicate that the practice of textual production in schools should be rethought, becoming more significant in its different contexts.
\end{abstract}

Keywords: textual production; teaching practice, textual correction and intervention plan.

\section{Introdução}

Em qualquer situação do nosso cotidiano, a linguagem falada é mais fácil que a escrita. No entanto, na sociedade atual, saber ler e escrever torna-se essencial.

De acordo com Geraldi (2004, p.19) “A construção de conceitos se faz com e na

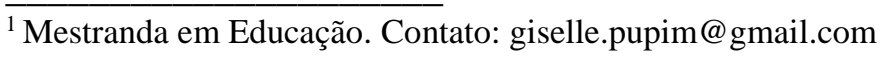


linguagem, porta a trabalhar quer por aprendizes, quer por ensinantes: sem a linguagem, a relação pedagógica o inexiste, sem a linguagem, a construção e a transmissão de saberes são impossíveis."

Pede-se aos nossos alunos pelo menos uma produção textual por semana, no entanto, cada vez que necessitamos escrever algo, temos uma grande resistência perante uma folha de papel em branco. Circunstancialmente, na maioria das vezes, a produção é sinônimo de incapacidade e insegurança, até mesmo para professores graduados. Contudo, mesmo compondo nossa rotina diária e tendo um amplo espaço nas pesquisas e estudos, a escrita ainda continua sendo o grande vilão. Isso leva diversos estudiosos a essa área de pesquisa. Vera (1979: 97) afirma que

O objeto de uma pesquisa - o problema - pode surgir de circunstâncias pessoais ou profissionais, da experiência científica própria ou alheia, da sugestão proveniente de uma personalidade superior, do estudo, da própria cultura, da leitura de grandes obras, etc. Em todos os casos, trata-se de uma questão que se nos apresenta com certa sutileza, que move nosso interesse e nos convida a buscar uma solução.

Após a difícil tarefa de elaborar o texto, evidencia-se outro obstáculo: a correção. Perante essa tarefa, a correção de texto tornou-se uma prática docente. Afinal, como ensinar produção de texto sem corrigi-lo? Há outra possibilidade? Nessa caminhada, nós, professores, nos questionamos como podemos fazê-la da melhor forma possível para que haja um avanço significativo.

Dentre as inúmeras tarefas do professor, a mais importante é, sem dúvida alguma, o ensino de produção de textos. O trabalho docente sempre se volta para o universo da leitura e da escrita, cabendo ao professor propiciar situações para a inserção dos alunos nessas práticas - de leitura e escrita - instituídas socialmente.

Na visão de Dolz e Scheneuwly (2004), para que o indivíduo se aproprie do ato de ler e escrever, além do interacionismo intersubjetivo (aquele que acontece mediante contextos de interações naturais), é necessário que ocorra o interacionismo instrumental, onde o educando descobre as determinações sociais das situações sociais das situações de comunicação e o valor das unidades linguísticas em seu uso efetivo. Para isto, as intervenções sistemáticas do professor desempenham um papel central para as transformações das interações entre o aprendiz e o texto.

Rojo (2001) reconhece que existam situações de comunicação como as descritas acima - de objetivação dos gêneros na escola - no entanto, são denominados pela mesma como gêneros escolarizados e definidos: 
[...] gêneros que vivem e circulam em outras esferas sociais de comunicação, como a esfera literária, jornalística, artística (musical), cotidiana, propagandística etc. (poemas, notícias, depoimentos, letras de canção, relatos de experiência vivida, discussões argumentativas, rótulos, logomarcas etc.), que são transpostos para sala de aula com a finalidade de servirem de suportes a atividades e práticas e/ou de particular de objetos de análise para a construção de conceitos linguísticos [...]. É o que a literatura aplicada do campo tem chamado de "texto como pretexto". Esta transposição, é claro, altera a dinâmica, a forma composicional, temática e estilística destes gêneros, transformando-os em gêneros didatizados (ROJO, 2001, p. 19).

Como bem aponta Bakhtin (2006, p. 123):

A verdadeira substância da língua não é constituída por um sistema abstrato de formas linguiísticas nem pela enunciação monológica isolada, nem pelo ato psicofisiológico de sua produção, mas pelo fenômeno social de interação verbal, realizada através da enunciação ou das enunciações. A interação verbal constitui assim a realidade fundamental da língua.

Partindo-se do princípio que, analisar os métodos de correção adotados pelo professor compreende uma reflexão sobre sua prática pedagógica e, sobretudo, ao funcionamento e ao processo de ensino e de aprendizagem de gêneros discursivos, a proposta se justifica, na medida em que se faz necessário compreender o processo de ensino e de aprendizagem destes alunos. Verdadeiramente, estudar a correção pode contribuir para o redimensionamento das práticas de ensino.

Não objetivamos responder ou solucionar essas inquietações. O que se pretende aqui é fomentar alguns questionamentos e trazer o assunto para a discussão coletiva, procurando abrir espaço que norteie as dúvidas e as inseguranças, trazendo contribuições significativas.

\section{A produção de texto como prática social}

Muitos avanços ocorreram na linguagem escrita, gerando transformações na oralidade, no discurso e, consequentemente, na aprendizagem e no processo dessa aprendizagem. $\mathrm{O}$ princípio de que uma criança deveria primeiramente se apropriar dos elementos da língua portuguesa (como o alfabeto - sílabas - palavras - frases - oração - texto) para somente assim produzir textos sociais, vem sendo substituído por novas concepções de ensino-aprendizagem.

Essas concepções defendem a escrita espontânea como princípio de aprendizagem. Conforme afirma Soares (1999, p. 51), os erros cometidos pelas crianças fazem parte da 
construção da escrita, sendo assim construtivos. A partir dessa análise, um aluno do primeiro ano pode sim produzir textos sociais mesmo sem ter se apropriado integralmente da língua portuguesa.

Ele pode produzir esses textos partindo do pressuposto que a verdadeira substância da língua é formada por um fenômeno social, com a finalidade de comunicação, sendo assim necessita muito mais do que simples letras, necessita de uma interação entre sujeitos (BAKHTIN/VOLOCHİNOV, 2006, p. 123). É através de relações com o outro que a linguagem deixa de ser isolada e passa a gerar experiências. Assim, podemos afirmar que a formulação de um discurso ou de um texto, parte das intenções e do contexto sócio-cultural ao qual o sujeito está inserido. $\mathrm{Ou}$, como o próprio autor refere-se, cada discurso apresenta marcas características da esfera social que está inserido.

\section{A produção de texto no espaço escolar}

Quando se propunha uma produção textual nas aulas, à principal finalidade era configurar quais conceitos ortográficos e gramaticais tinham sido assimilados e quais precisavam de maior atenção, porém, não privilegiando a função discursiva, a perspectiva intencional, a finalidade e nem tão pouco a função social dessas produções. Considerando esse cenário, os Parâmetros Curriculares Nacionais reformulam em 1998 a concepção de produção textual, permitindo respostas ás demandas sociais, adquirindo um caráter social. A partir de então, o aluno deveria ter contato com cartas, bilhetes, listas de comprar e outros gêneros discursivos que o levassem a compreender, que fora das paredes da sala de aula, há um mundo a ser explorado e principalmente lido e aprendido.

Ficando esse papel a responsabilidade do professor, mostrando que as produções devem ser bem mais que a apropriação de regras da língua portuguesa, elas passam a ser os olhos de quem quer enxergar além e os lábios de quem quer deixar sua marca na história.

É somente com a publicação deste PCN que a produção textual passa a ser analisada com olhares da sociedade. Os alunos passam a entender que quando se escreve, deve-se escrever para alguém ler, atingindo assim, um objetivo com contextualização. Antunes (2005, p. 32) nos recorda que o ato da escrita é uma atividade intencional e que cada texto tem um objetivo determinado. 
No entanto, para que esse escritor possa redigir um texto corretamente e que este posso ser lido corretamente, necessariamente precisa-se conhecer algumas regras gramaticais e ortográficas. Além disso, é de extrema importância que saiba pontuar também. Convém notar que o aluno precisa dispor de conhecimentos da língua portuguesa para que suas idéias sejam transmitidas.

Mas não basta somente ter conhecimentos lingüísticos, precisa ter conhecimentos sobre o assunto ao qual se quer redigir. Conhecimento este, proporcionado pelas diversas leituras e suas memórias sobre determinado assunto. E por último, conhecer o contexto histórico e cultural sobre ele.

Diante disso, percebe-se que a produção textual é uma arte bem mais complexa do que simples palavras soltas no papel. Todos esses conhecimentos, possivelmente, serão repassados ao leitor e compartilhados, sequencialmente, entre leitor e escritos, passando a serem uma prática social e não mais individual.

\section{A diversidade de gêneros textuais e sua importância em sala de aula}

\section{A escrita na história}

Diferentemente de nosso pensar hoje, ensinar a infância no século XIX não era prioridade uma vez que, a educação era vista como uma maneira de dominar a camada popular. No contexto mercantilista, os professores vendiam suas aulas em meio às feiras tornando o acesso á educação, somente para aqueles que possuíam dinheiro para comprá-la.

Com as mudanças tecnológicas e o desenvolvimento social, a escrita toma uma forma indispensável à vida humana. Através de bilhetes, post, anúncios, e-mail ou tantas outras maneiras de se comunicar, ela acaba sendo parte do meio ao qual o indivíduo está inserido.

Portanto, é através da prática da escrita que podemos anexar à aquisição de nossa língua materna onde, montada sobre um contexto sócio-histórico-cultural, revela como compreendemos o mundo e a nós mesmos. Para Koch (2010, p.33), “ [...] a escrita é entendida como uma atividade por meio da qual aquele que escreve expressa o seu pensamento"

A importância de se ter o domínio da língua oral e escrita está explicitada também nos Parâmetros Curriculares Nacionais (1997, p. 15): 
O domínio da língua, oral e escrita, é fundamental para a participação social efetiva, pois é por meio dela que o homem se comunica, tem acesso à informação, expressa e defende pontos de vista, partilha ou constrói visões de mundo, produz conhecimento. Por isso, ao ensiná-la, a escola tem a responsabilidade de garantir a todos os seus alunos o acesso aos saberes linguísticos, necessários para o exercício da cidadania, direito inalienável de todos.

\section{Tipologia X Gênero}

Ao longo de nossas vidas produzimos textuais orais e escritos, sendo estes, classificados conforme suas estruturas formais ou finalidades. Quando observamos as estruturas específicas do texto, como as regras gramaticais, dependendo de suas características, pensa-se em partes formais e respectivas tipologias textuais. A partir do momento que levamos em consideração a finalidade do texto, os interlocutores e, até mesmo a situação que essa comunicação acontece, falamos em gêneros textuais. Deste modo, podem-se classificar os textos, quanto às tipologias textuais, em: narração, descrição, dissertação, exposição e injunção.

A narração conta com ações e personagens. Mais antiga das tipologias, era usada desde o tempo das cavernas, quando o homem usava desenhos nas paredes para narrar suas caças. Já na descrição, o leitor precisa criar uma imagem do que está sendo descrito - a exemplo, a descrição de um monumento histórico. Enquanto na dissertação, há um debate sobre determinado assunto, expondo pontos de vistas e opiniões, na exposição procura-se esclarecer sobre determinado assunto, contrariando assim a dissertação, onde não há a emissão de opiniões. Finalizando, a injunção emite orientação sobre o uso de determinado aparelho, ditando regras ou instruindo.

Dentro dessas cinco tipologias, classificam-se os gêneros textuais seguindo o objetivo que se quer atingir com determinado texto. Podemos elencar alguns, no entanto, deve-se ficar claro que os gêneros textuais são infinitos, uma vez que a sociedade também apresenta modificações a todo instante e os gêneros textuais estão intimamente ligados a ela. Cada gênero textual apresenta seu próprio estilo e configura-se assim por manifestações socialmente reconhecidas. Cita-se aqui as cartas, histórias em quadrinhos, e-mail, contos de fadas dentre tantos. 


\section{Gêneros textuais e a sala de aula: combinação que dá certo...}

Ao se trabalhar gênero textual em sala de aula, deve-se ir além das características formais. Explicar aos alunos que nas fábulas há um ensinamento ou que a carta precisa ter cabeçalho e saudações, não permitirá sozinho que os alunos compreendam o gênero, sendo capaz de redigi-lo. $\mathrm{O}$ aluno precisa fazer para aprender. Trabalhar somente as partes formais do texto é menos trabalhoso para o professor, mas não garante a aprendizagem por parte do aluno. "O que importa é fazer a garotada transitar entre as diferentes estruturas e funções dos textos como leitores e escritores", explica a linguista Beth Marcuschi, da Universidade Federal de Pernambuco (UFPE).

Assim não há como um aluno produzir um texto somente para seu professor ler. Quando solicitado a escrita de uma notícia, precisa compreender que será lido por diversas pessoas e que alguns pontos devem ser observados, inclusive as regras gramaticais.

Ao se trabalhar diversos gêneros textuais, há que se dar suporte aos novos escritores. Essa exploração precisa sair das páginas do livro didático, buscando outros exemplos sociais. Para que haja aprendizado há que se seguirem os passos - ouvinte - leitor - escritor pois, ao ouvirem a leitura vão se familiarizando com as características dos gêneros textuais, apreciando e compreendendo. Em consonância, no ato da leitura comparam versões, observam os recursos lingüísticos usados pelos autores e, ao produzirem, colocam em prática os conhecimentos adquiridos nos passos anteriores, inclusive a gramática e a ortografia.

\section{Correção pela correção não tem fundamento...}

Das ações desempenhadas pelo professor, em especial um pedagogo, destaca-se a atividade de correção de textos. Tendo este importante papel, a pergunta central que envolve a experiência é: Será que o educador deve realizar intervenções sistemáticas entre o aprendiz e o texto escrito pelo próprio aluno? Será que ao reescrever um texto, o aluno se apropria de novos conhecimentos linguísticos que contribuem para o seu efetivo desenvolvimento?

Nos processos de produção textual faz-se necessário que o texto tenha sentido para o leitor uma vez que, quando se coloca a frente de uma produção, precisa buscar sentido logico nele. Segundo Miller (1998:10), “quando se escreve, está em jogo produzir um texto que faça 
sentido para o leitor e, da mesma forma, quando o leitor coloca-se diante de um texto escrito, está em jogo buscar o sentido nele expresso."

Para tanto, o ato de produzir um texto deve ser significativo para o educando, pois, o mesmo deve levar em consideração outros pontos tais como a coesão, coerência, argumentação, organização de ideias, dentre outros. Deste modo, cada texto tem sua função e todas essas possíveis manifestações escritas devem ser trabalhadas em sala de aula. Sobre isso, os PCNs (BRASIL, 1997, p. 24) esclarecem:

\begin{abstract}
Uma rica interação dialogal na sala de aula, dos alunos entre si e entre o professor e os alunos, é uma excelente estratégia de construção do conhecimento, pois permite a troca de informações, o confronto de opiniões, a negociação dos sentidos, a avaliação dos processos pedagógicos em que estão envolvidos.
\end{abstract}

Dessa forma, a sala de aula deixa de ser apenas um lugar de transmissão/recepção de um conhecimento arbitrário e passa a ser um "evento social no qual, através de procedimentos interacionais, professor e alunos tentam construir significado e conhecimento" (MOITA LOPES, 1996, p. 349).

Assim, ao escrever um texto torna-se imprescindível que:

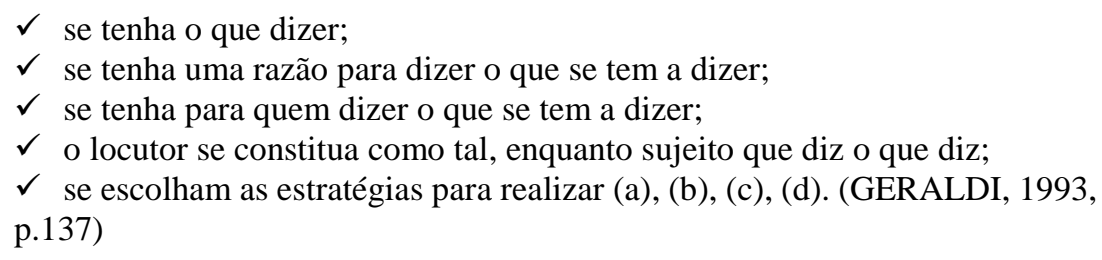

Sabe-se que os itens descritos acima não são de fácil realização até mesmo para alunos universitários. Contudo, para que esta dificuldade seja atenuada, os educadores das séries iniciais precisam desenvolver um trabalho adequado.

Percebe-se que as práticas de produções acontecem nas salas de aula de formas isoladas e desconectadas do contexto popular. Em diversas situações os textos não passam de meros papéis que sempre ficam guardados em pastas nos armários da escola, sendo lidos uma vez ou outra, simplesmente para mera verificação, nunca havendo uma discussão ou apresentação em retorno do que o aluno produziu, mesmo havendo inúmeras sugestões. Á exemplo:

É preciso que, para cada criança, o escrever não seja sinônimo de trabalho enfadonho, fracasso, mas que evoque, em vez disso, projetos realizados graças à escrita: é preciso escrever, seja fazer um cartaz para anunciar uma exposição, fazer um relatório de visita, escrever poemas etc., em lugar de fazer exercícios 
de gramática, completar frases, fazer ditados, etc. (JOLIBERT e Colaboradores, 1994: 16)

Em alguns estudos, Ruiz (2001) investiga como se corrige produções textuais na escola, expondo como acontece a prática de correção textual de um determinado grupo de professores do ensino básico, que trabalha com reescrita e, a que resultados eles chegaram. Nessa pesquisa, Ruiz cataloga quatro tipos de correções que são assim descritas, com base em Serafini (1989):

a) correção resolutiva: solução dos problemas detectados nos textos;

b) correção indicativa: marcas deixadas no texto para apontar os problemas encontrados;

c) correção classificatória: marcas de metalinguagem codificada para apontar a natureza dos problemas encontrados nos textos;

d) correção textual-interativa: bilhetes deixados pelo professor, os quais visam estabelecer interlocução com o aluno sobre problemas e acertos no texto.

A correção tem como objetivo chamar a atenção do aluno para determinado problema (RUIZ, 2001). Percebe-se, então, que a ação de correção efetuada pelo professor toma uma dimensão importantíssima para o desenvolvimento de sua função como educador. No entanto, ela deixa de ser somente uma ação desenvolvida por uma classe de profissionais instituídos socialmente e passa a auxiliar no processo de ensino e de aprendizagem da escrita. Isso porque é por ela que o aluno percebe o que é ou não pertinente para seu texto, e também, pela correção, o professor expõe, para o aluno, quais os problemas existentes em seu texto. O que, por via de regra, deveria gerar uma reflexão sobre a escrita.

Ruiz (2001: 215) assinala que "a correção pela mera correção não tem fundamento". Detalha ainda, que "os sinais de correção empregados pelo professor são as marcas que ele deixa para o aluno (e para nós, analistas), do seu projeto de dizer”. Esse processo de análise e correção do professor no texto do aluno, pode oferecer uma boa contribuição para a reflexão da linguagem escrita. A análise da ação de correção proposta neste trabalho volta-se para as atividades de retextualização e separação de item gerado pelas dificuldades dos alunos.

Marcuschi (2001:70), em trabalho sobre retextualização, afirma que "para poder transformar um texto é necessário compreendê-lo ou pelo menos ter uma certa compreensão dele". Para que isso aconteça, é necessário se ter um texto como base para uma posterior elaboração do conceito do gênero. Ainda para o autor citado anteriormente, para retextualizar, é preciso compreender o texto "principal".

Neste aspecto as atividades sugeridas devem conter gêneros do domínio do aluno, para que ele desenvolva os conceitos científicos para a assimilação do gênero. Ao se iniciar esse tipo 
de aprendizagem faz-se necessário saber o que o aluno apresenta de conhecimento sobre o assunto. Para Moscovici (2003: 52), “existe um comportamento adequado para cada circunstância, uma fórmula linguística para cada confrontação e (...) a informação apropriada para um contexto determinado".

Marcuschi (2002, p. 20) afirma que:

Fruto de trabalho coletivo, os gêneros contribuem para ordenar e estabilizar as atividades comunicativas do dia-a-dia. São entidades sócio-discursivas e formas de ação social incontornáveis em qualquer situação comunicativa. Os gêneros textuais surgem, situam-se e integram-se funcionalmente nas culturas em que se desenvolvem.

Após essas análises, algumas questões norteiam nosso estudo. Sejam: (1) como o professor inicia a produção textual?; (2) como a correção do professor influencia no processo de aprendizagem?; (3) como o professor corrige?; (4) o que o professor valoriza em sua correção? e, (5) Que tipo de trabalho com gêneros discursivos desenvolve o domínio da língua padrão e da autoria?

\section{Análise de dados}

Ao se refletir um tema do interesse de muitos professores, pretendeu-se dar uma pequena contribuição para solucionar uma das muitas dificuldades que identificamos nessa trajetória profissional. Objetivou-se compreender o processo de escrita e correção textual por meio de três gêneros discursivos (conto, poesia e história em quadrinhos), enfatizando o desenvolvimento da autoria. Para analisar a prática da produção textual no ambiente escolar, optou-se pela amostragem, escolhendo-se de forma aleatória, textos produzidos por discentes do quinto ano (Ensino Fundamental I). Também, documentos que nos oriente teoricamente, sob o olhar de autores como Geraldi, Bakhtin, Rojo, Beth Brait Ruiz, Marcuschi, Parâmetros Curriculares Nacionais, bem como entrevista com o professor regente e pesquisa in loco

$\mathrm{Na}$ entrevista aplicada observou-se que a maior dificuldade dos docentes é realizar as correções textuais de todos os alunos. Referindo-se aos fatores que dificultam ou impedem a correção textual, os docentes enumeram elementos como: tempo insuficiente e quantidade excessiva de alunos. As falas dos professores presentes nas entrevistas e os textos elaborados pelos alunos constituíram-se no material documental do qual se pôde recolher os dados para serem analisados. Um "recorte de respostas" foi utilizado para ilustrar a análise. 
Tomando como base as questões elencadas anteriormente, a professora I descreve que sempre trabalha com o livro didático e as produções complementam o gênero textual elencado. Segundo relato, se o gênero textual é história em quadrinhos, após a leitura e diversas interpretações ela pede a produção. Já a professora 2, afirma trabalhar diversos gêneros em uma mesma unidade para garantir que todos seus alunos tenham contato com todos os gêneros até o final do ano letivo.

A próxima questão destacada foi como essas correções auxiliam no processo de ensino-aprendizagem. Como salienta a professora "A", a cada produção textual, consegue atender ao máximo cinco (5) alunos da turma, procurando sentar-se ao lado daqueles que requerem mais atenção ou utiliza de monitores para auxiliá-los, mas nem sempre consegue atender efetivamente a todos e inúmeras vezes precisa parar seu trabalho para atende os outros alunos. Sendo assim, afirma que a maioria das produções acaba sendo coletivas. Já a professora "B", acaba levando os textos para serem corrigidos na sua hora de trabalho pedagógica ou mesmo em casa, mas admite que raramente retome os textos anteriores para análises ou reescritas. A professora "I" utiliza a legenda de correções desenvolvida com a participação dos alunos e a cada produção é elencada qual item será corrigido, afirmando que com essa estratégia consegue ler e corrigir todos os textos e dar as devolutivas necessárias. Complementa dizendo que os alunos pesquisam em dicionários, livros literários e livros didáticos a maneira correta de escrita e retomam os textos para correção observando assim, um avanço na escrita dos alunos - "além de errarem menos os textos tornam-se mais coerentes a cada dia".

Em suas correções os professores "2", "A" e "B" afirmam fazer uso de canetas sobre os erros ortográficos de seus alunos e que quando devolvem esses textos, pedem que os mesmos observem-nos, mas acreditam que agindo dessa forma os discentes não conseguem superar esses desafios, pois se tornam meros copistas da escrita que o professor fez. A professora "1" relata que tentou grifar os erros de seus alunos e pedir que eles consultassem a maneira correta, no entanto isso só foi possível duas vezes, pois nesses dias havia uma estagiária na sala que a auxiliou, porém, nos demais dias faz um trabalho solitário. A professora "2", antes de entregar a proposta textual para os alunos confirma qual item da legenda será contemplado, se letra maiúscula, minúscula, ortografia, segmentação, acentuação ou paragrafação. Em desabafo diz que, quando iniciou o trabalho dessa maneira ficou receosa, pois acreditava que seus alunos não iriam errar na segmentação, uma vez que a correção era essa, mas que no próximo texto não se preocupariam com esse item. No entanto afirma, que o desenvolvimento do trabalho surpreendeu suas expectativas e, não só deixaram de errar nas produções, mas também nas 
outras disciplinas afins ou não. A professora também elencou a importância de cada aluno ter seu caderno de produção textual separado do restante do material, uma vez que assim poderiam ver seus avanços.

Na pesquisa in loco, a base foi à observação de um plano de intervenção pedagógica desenvolvido em etapas e realizado com alunos de uma mesma turma de Ensino Fundamental I pela professora " 2 ". Inicialmente, o professor regente solicitou a reescrita de um texto conhecido pelos alunos. No entanto, esse texto foi utilizado como um diagnóstico. Porém, não foi corrigido e nem sofreu intervenções.

Analisaram-se essas produções e planejaram-se ações de intervenção para a turma. Dentre as ações, há a elaboração de uma legenda que permitirá ao professor corrigir todos os textos dos alunos, realizando as devidas devolutivas. Os gêneros textuais propostos para produção foram trabalhados interdisciplinarmente, sendo assim ao escrever seu texto os alunos já tinham uma base conceitual do gênero.

A cada semana foram realizados momentos de leituras frequentes nas salas e as produções aconteciam em três momentos distintos. Primeiramente, uma produção coletiva para os alunos compreenderem a caracterização do gênero textual, bem como paragrafação, coerência e coesão. Em um segundo momento, uma produção individual embasada no gênero trabalhado e, por último uma tarefa para casa. No dia seguinte, com essas produções realizadas, um aluno se dispunha a emprestar seu texto para a professora reescrevê-lo na lousa, na íntegra, e os demais colegas ajudaram nas correções, caso necessário. Em seguida todos copiavam o texto como forma de registro.

\section{Considerações finais}

As reflexões levantadas permitiram compreender que é possível a produção textual e a correção de todas as propostas apresentadas, partindo de um plano de intervenção bem elaborado. Sendo assim, cabe ao educador desenvolver uma metodologia diferenciada que permita aos estudantes avançar no domínio dessa leitura e dessa produção textual. Porém, especificamente, buscou-se demonstrar como realizar correções textuais de todos os alunos e possibilitar a retomada do texto escrito.

Quanto aos resultados das entrevistas com os professores, pode-se perceber que são inúmeros os desafios enfrentados, tanto nas atividades de escrita quanto nas de correção. Em consonância, na continuidade de metodologias tradicionais vivenciadas pelos mesmos em sua 
fase escolar, evidenciou-se que muitos continuam fazendo as mesmas correções que eram realizadas por seu professor há vinte anos. Observou-se também, a ausência de auxílio aos professores nos dias que irá se trabalhar a produção, afirmando ser um trabalho totalmente solitário. Portanto, não há um plano de trabalho da coordenação para auxiliar ou amenizar esses anseios. Contudo, deparou-se com profissionais que, mesmos solitários, realizam estratégias metodológicas que permitam aos seus alunos progredirem, conseguindo fazer de seus alunos sujeitos hábeis na compreensão e na construção de significados, através das atividades de leitura e escrita. Embora o ensino da Língua Portuguesa se mostre ineficiente, Chiappini (1997, p. 23) revela que os professores têm buscado cada vez mais integrar o texto no trabalho com a linguagem.

De acordo com Marcuschi (2008, p. 209), em sala de aula "consideram-se apenas os gêneros com realização linguística mais formal e não os mais praticados nas atividades cotidianas". Relata ainda:

Os PCNs não negam que haja mais gêneros, mas estes não são lembrados. Porque não trabalhar telefonemas, conversações espontâneas, consultas, discussões etc., para a fala? Porque não analisar formulários, cartas, bilhetes, documentos, receitas, bulas, anúncios, [...] diários, ata de condomínio e assim por diante, para a escrita?

Percebe-se assim, a utilização da produção textual mais como uma forma de avaliação do que uma ferramenta de aprendizagem. Também, o livro didático sendo muitas vezes o único recurso de leitura desses alunos. Diante dos fatos, isso faz com que gere um empobrecimento na capacidade leitora de nossos discentes. Necessitamos aguçar mais a leitura de nossos alunos e possibilitar a retomada das produções realizadas por eles.

No entanto, essas discussões não devem ficar somente em sala de aula. Precisamos atentar "o" olhar para as formações continuadas da escola, aos cursos de formação em Língua Portuguesa e Universidades. Essas reflexões devem transcender os muros escolares para que possibilite mudanças eficazes e eficientes.

\section{Referências}

BAKHTIN, M. Estética de criação verbal. São Paulo: Martins Fontes, 1997. 
BRASIL. Ministério da Educação e do Desporto. Parâmetros Curriculares Nacionais -Língua Portuguesa-3 ${ }^{\circ}$ e $4^{\circ}$ ciclos.Brasília:MEC, 1998

GERALDI, João Wanderlei. Da redação à produção de textos. In: Chiappini, L. (Coord.) Aprender e ensinar com textos de alunos. 6. ed.São Paulo: Cortez, 2004. v. 1.

JOLIBERT, J. (coord.) Formando crianças produtoras de textos. Porto Alegre: Artmed, 1994, v. II.

KOCH, Ingedore Grunfeld Villaça e ELIAS, Vanda Maria. Ler e escrever: estratégias de produção textual. 2. ed. São Paulo: Contexto, 2010.

1.Leitura, texto e sentido; 2.Leitura, Sistemas de conhecimento e

Processamento Textual; 3. Texto e Contexto; 4. Texto e Intertextualidade; 5. Gêneros

Textuais. In: Ler e Compreender os sentidos do texto.3. ed. São Paulo: Contexto, 2009.

MACHADO, A. R.; ABREU-TARDELLI, L. S.; LOUSADA, E. Trabalhos de pesquisa: diários de leitura para a revisão bibliográfica. São Paulo: Parábola. Editorial, 2007.

MARCUSCHI, Luiz Antônio. Da fala para a escrita: atividade de retextualização. 2 ed.São Paulo: Cortez, 2001.

Gêneros textuais: definição e funcionalidade. In: Dionísio, Ângela Paiva; Machado, Anna Rachel; Bezerra, Maria Auxiliadora (Org.). Gêneros Textuais e Ensino. RJ: Lucerna, 2002.

Editorial, 2008 .

Produção textual, análise de gêneros e compreensão. São Paulo: Paráabola

MATENCIO, Maria de Lourdes Meirelles. Estudo da língua falada e aula de língua materna: uma abordagem processual da interação professor/alunos. - Campinas, SP: Mercado de Letras, 2001.

Atividades de (Re) textualização em práticas acadêmicas: Um estudo do resumo. Scripta, Belo Horizonte, v.6, n.11, p.109-122, $2^{\circ}$ sem. 2002.

Referenciação e retextualização de textos acadêmicos: um estudo do resumo e da resenha. Anais do III Congresso Internacional da ABRALIN. Rio de Janeiro, março de 2003.

MATENCIO, Maria de Lourdes Meirelles e SILVA, Jane Quintiliano Guimarães. Retextualização: movimentos de aprendizagem. Anais do II Encontro Internacional: Um estudo sobre a correção de textos: diário de leitura. Volume 4 - Número 1 - Ano IV $\operatorname{dez} / 2011$.

MILLER, S. O epilinguístico: uma ponte entre o linguístico e o metalinguístico. 1998. 185f. Tese (Doutorado em Educação) - Faculdade de Filosofia e Ciências, Universidade Estadual Paulista, Marília, 1998. 
MOITA LOPES, L. P. Oficina de lingüística aplicada. Campinas, SP: Mercado de Letras, 1996.

MOSCOVICI, Serge. Representações sociais: investigação em psicologia social.

Tradução de Pedrinho A. Guareschi. Petrópolis, RJ: Vozes, 2003.

ROJO, R. H. R. A prática de linguagem em sala de aula: praticando os PCNs. Campinas: EDUC/Mercado de Letras, 2000.

RUIZ, Eliana Maria Severino Donaio. Como se corrige redação na escola. - Campinas, SP: Mercado de Letras, 2001.

SCHNEUWLY, B. E DOLZ, J. (Org) Gêneros orais e escritos na escola. Campinas: mercado de Letras, 2004.

SOARES, M. Aprender a escrever, ensinar a escrever. In: ZACCUR, E. A magia da linguagem.Rio de Janeiro: DP\&A, 1999.

VERA, A. A. Metodologia da pesquisa científica. 5. ed. Tradução de Maria Helena GuedesCrespo e Beatriz Marques Magalhães. Porto Alegre: Globo, 1979.

Como citar este artigo (Formato ABNT):

BACK, Giselle Pupim Jorge. Diversidade Textual em Sala de Aula. Id on Line Rev.Mult. Psic., 2018, vol.12, n.42, Supl. 1, p. 703-717. ISSN: 1981-1179.

Recebido: 19/04/2018;

Aceito: 16/11/2018 